\title{
Technology acceptance model for computer assisted personal interviewing
}

\author{
Margaretha Ari Anggorowati a,1,* \\ ${ }^{a}$ Sekolah Tinggi Ilmu Statistik, Jakarta, Indonesia \\ 1 m.ari@stis.ac.id \\ * corresponding author
}

\begin{tabular}{ll}
\hline ARTICLE INFO & ABSTRACT \\
\cline { 2 - 2 } $\begin{array}{l}\text { Article history } \\
\text { Received November 12, 2016 } \\
\text { Revised December 14, 2016 } \\
\text { Accepted January 11, 2017 }\end{array}$ & $\begin{array}{l}\text { Data collection plays an important role in census and survey for statistical } \\
\text { work. Badan Pusat Statistik (BPS) Indonesia spent a lot of effort on human } \\
\text { resources, budget, and time and complexity management in order to have } \\
\text { valid data. Computer Assisted Personal Interviewing (CAPI) is a system } \\
\text { which support data collection process more simple and efficient. It important } \\
\text { to measure the user acceptance of CAPI in statistical work. }\end{array}$ \\
Keywords &
\end{tabular}

TAM

SEM

CAPI

This is an open access article under the CC-BY-SA license.

\section{Introduction}

Data quality directly and indirectly will influence government policy. Badan Pusat Statistik (BPS) Indonesia conduct many census and survey in order to supply data for government and society. The most using of budget in census and survey for data collection and data entry. In traditional way, the data collection has been conducted using questioner/ Paper and Pencil Interviewing (PEPI). This method even though face to face interview, has some limitations: (1) PEPI needs data entry that takes time and budgeting, (2) there is no standardization how the interviewer fill the form. It will makes double interpretation, (3) there is possibility for typo mistake. Computer Assisted Personal Interviewing (CAPI) was developed in order to be a solution for PEPI limitation.

CAPI is a new method for data collection that using computer technology such as notebook, laptop and PC tablet [1]-[3]. CAPI employing system data entry that embedded in such computer and it is used for directly interview. The aim of CAPI implementation is for faster process of data collection, data processing and for accurate data entry. CAPI also has impact in budget reduction of survey/census. It is important to employ information technology to support how data collection and data entry can automatically run.

The important point for employing CAPI in survey or census is how user have a perception of this system and then have a willingness to use it. Based on the theory of Technology Acceptance Model [4] and a framework of diffusion technology [5], this research was conducted in order to answer these question: (1) how is TAM's model for CAPI STIS, (2) what factors which influence the user acceptance of CAPI and (3) what kind of supporting to user in order to get the optimum CAPI implementation?. 


\section{Theoritical Framework}

\subsection{Technology Acceptance Model (TAM)}

Technology Acceptance Model (TAM) is a model which use for explain the willingness of user to accept and use a new or specific technology. TAM was developed by Fred Davis in 1989. TAM is expanded of Theory of Reaction Action (TRA) which developed by Fisbein and Azjen in 1975 [6]. TAM has two main constructs, there are perceived ease of use (PEU) and perceived usefulness (PU) [7]. In three decade TAM was used for measuring various technology adoption. TAM has been employing for many kind researches of technology. TAM has been developed theoretically by expanding the variables or constructs.

Structural Equation Model (SEM) is a statistical method which is employed in 64\% validation of TAM model [8]. It means that SEM is powerful to explain relations among construct in TAM structure. SEM was employed to do statistical test for relation among constructs in TAM model.

\subsection{CAPI STIS}

CAPI STIS 2015 is a statics application it means that this application just specific for such survey. It is needed some hardcode (modify the coding program) if this application will be used for other survey. This application was developed specifically for an economic and social survey. Sekolah Tinggi Ilmu Statistik (STIS) BPS, employed CAPI in social and economic survey. The survey was conducted in 4 Kabupaten: Kabupaten Indramayu and Kota Bandung. There are 108 user CAPI who use CAPI application in data collection.

CAPI STIS 2015 is a statics application. This system was the constructs of TAM model was developed refer to TAM BPS [8]. There are perceived usefulness, perceived ease of use, training, output quality , and result demonstrability.

\section{Data and Model Structure}

Data collection was conducted by questioners among users. The indicators of variables were put in likert scale in order to describe the user's perception of CAPI system.

According to validity and reliability of each external variables (constructs), TAM CAPI structure of TAM model is shown in Fig. 1. The figure shows that there are 5 constructs in TAM model. The main constructs in TAM model are perceived ease of use and perceived of usefulness [9]. Output quality and result demonstrability have relation to perceived ease of use. Perceived ease of use and training have relation to perceive of usefulness. Output quality describe the user perception about the output of data entry using CAPI. The data will put in database in real time and will be save in server. For the next step of survey/census the data will be used for statistical analysis. Result demonstrability define how the user could be discuss and communicate around the result of CAPI system. Training explain the influence of training to users in order to have good skill in CAPI system. Perceived of usefulness describe the user perception whether the system help them to finish their work. Perceived ease of use explain the user perception whether the system is easy to be used.

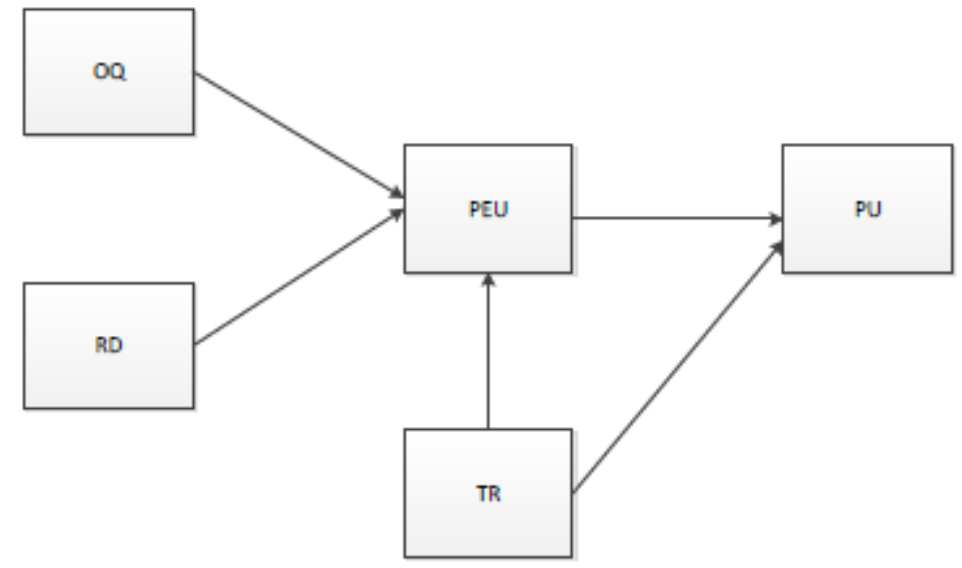

Fig. 1.TAM Structure 


\section{Analysis}

\subsection{Descriptive Analysis}

Descriptive analysis explain data characteristics and data distribution. The users as respondent are divided in two groups based on different survey. Based on Fig. 2, 63\% user use CAPI in social survey and $37 \%$ user use CAPI in economics survey.

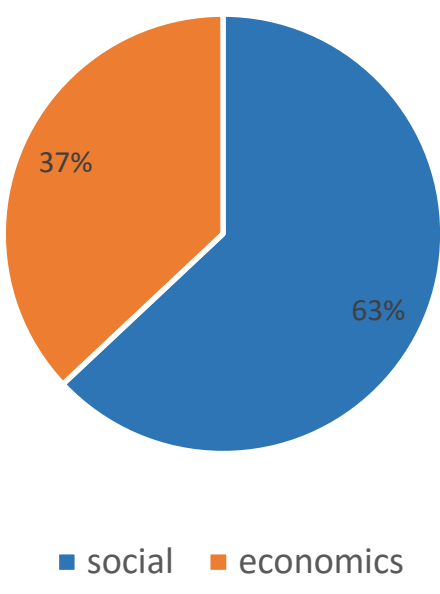

Fig. 2.User based on survey

Different survey will conduct different type of data entry, different rule validation and different design interface of CAPI system. The differences may have different influences user acceptance.

Fig. 3 shows user experience is one of the TAM constructs. Having knowledge of the user experiences is very important to understand the user acceptance of the users.

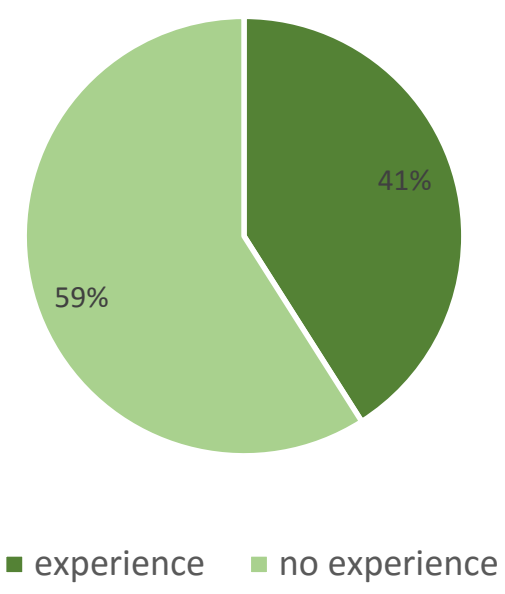

Fig. 3.User experience

Fig. 4 explain subjective norm explain that most of users have perception that they friends and lecture said that CAPI application is important for data collection (61.42\% really agree, $33.3 \%$ agree). 


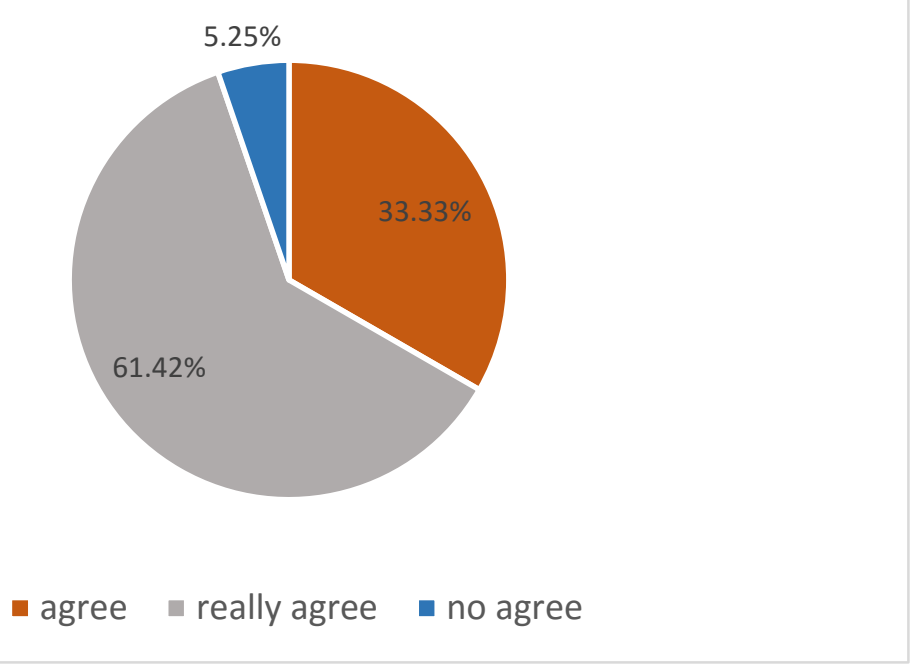

Fig. 4.Subjective norm

According to of TAM model, SEM structure was developed in order to validate the TAM. Fig. 1 shows the SEM structure for TAM CAPI model. SEM model consists of measurement model and structural model. Measurement model validate all indicators of variables and structural model validate the relations between variables in TAM model.

Fig. 5 shows that $33.64 \%$ users has perception that CAPI application does not have good output quality, in other side $10 \%$ and $49.38 \%$ user agree and really agree that CAPI has good quality. Fig. 6 shows that $8 \%$ users said that CAPI applications does not make data collection faster and efficient. In the other hand $31 \%$ agree and $61 \%$ really agree that CAPI applications helps data collections faster and more efficient.

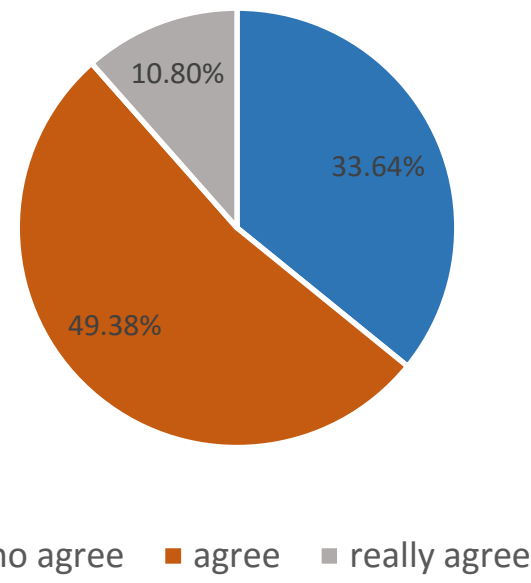

Fig. 5.Output quality 


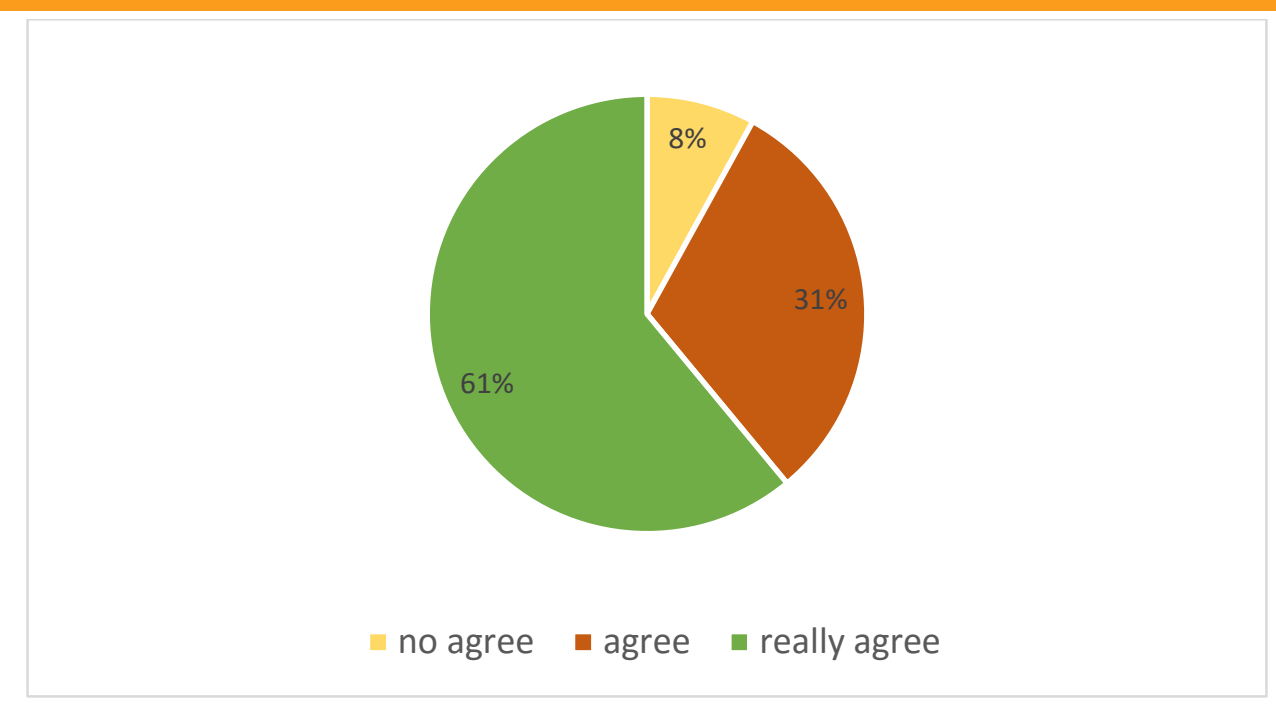

Fig. 6.Percieved of usefulness

Fig. 7 shows that $65.28 \%$ users agree and $27.78 \%$ really agree that CAPI application is easy to use, but $6.94 \%$ has perception that CAPI applications is not ease to use. Fig. 6 shows the users perception of the influence of training for using CAPI applications. $60.65 \%$ dan $29.63 \%$ users said that training help them to use CAPI bit $9.72 \%$ said that training is not to help them for using CAPI.

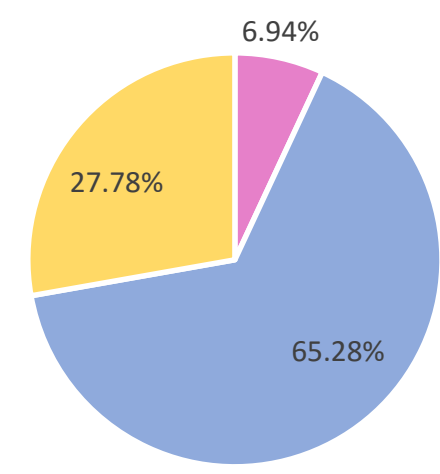

no agree agree really agree

Fig. 7.Percieved ease of use

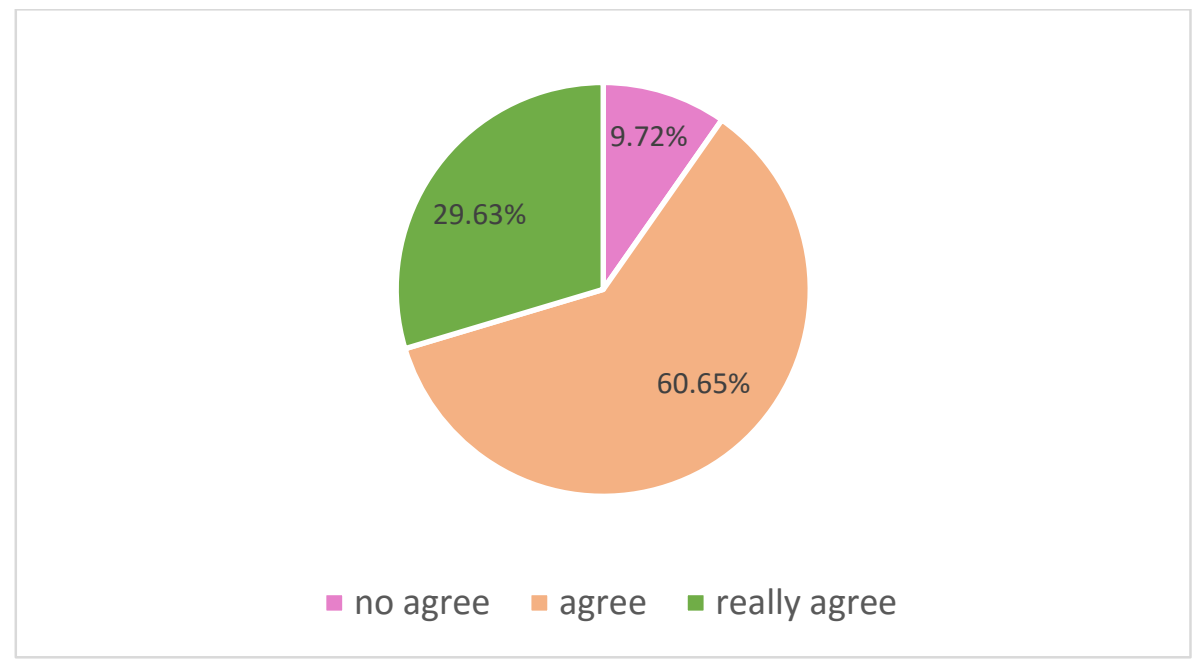

Fig. 8.Training 


\subsection{Validation Structure Using SEM}

Validation TAM structure was conducted by SEM analysis. SEM estimated all parameter which can explain the relation between constructs in TAM structure [10]. The estimation obtain value parameter of TAM model. Table 1 shows the parameters, the minimum value of $\lambda$ is 0.650 and the maximum is 0.919 . $\lambda$ explain the relation between indicators and variable/construct. Table 1 also explain the minimum value of is 0.165 and the maximum is 0.347 . Parameters explain relation between variables. Fig. 2 shows that output quality has positive influence significantly to perceived ease of use. Result demonstrability and training also has positive influence significantly to perceived ease of use. Training significant influence positively to perceived usefulness. Refers to Anggorowati, for the case of TAM BPS model perceived ease of use does not have influence significantly to perceive of usefulness [8].

The interpretation of the model explain that the output of data entry in database could be used in analysis. It means that data collection using CAPI system can replace the data collection using PEPI (Paper and Pencil Interviewing). The user also can discuss and communicated each other about the data and has no difficulties to use it. It explain that result demonstrability has significantly to perceived ease of use. Training of CAPI applications was conducted for all users. The training also involved role play as a simulation how to use CAPI in data collections. In the simulation there were some fisherman been interviewed by the users. The Training variable influence positively on perceived.

Ease to use and perceived of usefulness. It means that users has perceptions that training make them understand how to use the CAPI application and they can see how CAPI make data collections become easier and faster (more efficient). Relevance to TAM BPS perceived ease of use has no significant influence to perceived ease of use [8]. It explain that when the application is used in mandatory environment then no relation between perceived ease of use and perceived ease of use.

Table 1. Parameter model

\begin{tabular}{cccc}
\hline Parameter & Value & Parameter & Value \\
\hline$\lambda_{1}$ & 0.861 & $\lambda_{9}$ & 0.871 \\
$\lambda_{2}$ & 0.852 & $\lambda_{10}$ & 0.724 \\
$\lambda_{3}$ & 0.894 & $\lambda_{11}$ & 0.848 \\
$\lambda_{4}$ & 0.805 & $\lambda_{12}$ & 0.919 \\
$\lambda_{5}$ & 0.811 & $Y_{1}$ & 0.165 \\
$\lambda_{6}$ & 0.821 & $Y_{2}$ & 0.347 \\
$\lambda_{7}$ & 0.738 & $Y_{3}$ & 0.130 \\
$\lambda_{8}$ & 0.650 & $Y_{4}$ & 0.290 \\
\hline
\end{tabular}

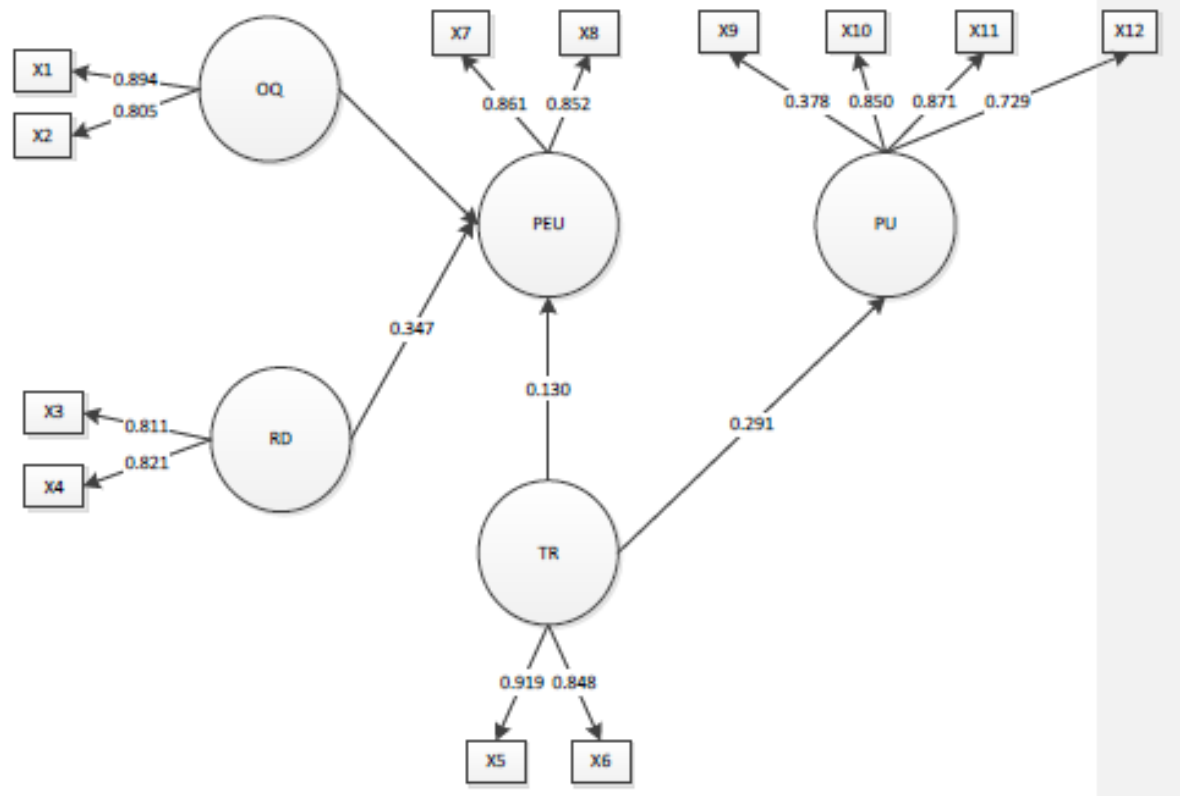

Fig. 9.Estimation of TAM Parameters 


\section{Conclusion}

CAPI application was proved can be implemented in survey and census data collections especially for social survey and economics survey. CAPI application made the data collection more efficient and effective (fast and easy). There are three variables which are influence the perceived ease of use and perceived of usefulness.

It is needed to be developed the dynamics CAPI application for many kind of survey data collection. This research lead to a new problem question: how management support should be conducted in order to enhance the implementation of CAPI applications.

\section{References}

[1] J. Gratch, G. M. Lucas, A. A. King, and L. P. Morency, "It's only a computer: the impact of human-agent interaction in clinical interviews," in Proceedings of the 2014 international conference on Autonomous agents and multi-agent systems, 2014, pp. 85-92.

[2] C. Leisher, "A comparison of tablet-based and paper-based survey data collection in conservation projects," Soc. Sci., vol. 3, no. 2, pp. 264-271, 2014.

[3] R. P. Baker, "New technology in survey research: Computer-assisted personal interviewing (CAPI)," Soc. Sci. Comput. Rev., vol. 10, no. 2, pp. 145-157, 1992.

[4] N. Marangunić and A. Granić, "Technology acceptance model: a literature review from 1986 to 2013," Univers. Access Inf. Soc., vol. 14, no. 1, pp. 81-95, 2015.

[5] W. Keller, "International technology diffusion," J. Econ. Lit., vol. 42, no. 3, pp. 752-782, 2004.

[6] O. C. Otieno, S. Liyala, B. C. Odongo, and S. Abeka, "Theory of reasoned action as an underpinning to technological innovation adoption studies," World J. Comput. Appl. Technol., vol. 4, no. 1, pp. 1-7, 2016.

[7] T. Ramayah and J. Ignatius, "Impact of perceived usefulness, perceived ease of use and perceived enjoyment on intention to shop online," ICFAI J. Syst. Manag., vol. 3, no. 3, pp. 36-51, 2005.

[8] M. A. Anggorowati, N. Iriawan, S. Suhartono, and H. Gautama, "Restructuring and Expanding Technology Acceptance Model: Structural Equation Model and Bayesian Approach," Am. J. Appl. Sci., vol. 9, no. 4, pp. 496-504, 2012.

[9] F. D. Davis, "Perceived usefulness, perceived ease of use, and user acceptance of information technology," MIS Q., vol. 13, no. 3, pp. 319-340, 1989.

[10] A. Mardani et al., "Application of Structural Equation Modeling (SEM) to solve environmental sustainability problems: A comprehensive review and meta-analysis," Sustainability, vol. 9, no. 10, p. $1814,2017$. 